\title{
AI Enhanced Person-Centred Care Services for Monitoring Stroke Outpatient Rehabilitation
}

\author{
Ramo ŠENDELJ $^{\mathrm{a}, 1}$, Ivana OGNJANOVIĆ ${ }^{\mathrm{a}}$, Milovan ROGANOVIĆ ${ }^{\mathrm{b}}$ and Dalia \\ KRIKŠČIŪNIENÉ \\ ${ }^{a}$ University of Donja Gorica, Montenegro \\ ${ }^{\mathrm{b}}$ Department of Neurology, Clinical Centre of Montenegro \\ ${ }^{\mathrm{c}}$ Vilnius University, Lithuania
}

\begin{abstract}
Development of person-centred care (PCC) services require adjustment to specific domain of application and integration with existing processes implemented in healthcare institution. This poster present PCC services for monitoring stroke outpatient rehabilitation, enhanced by modern ICT technologies (thus enabling adjustments to different kind of patients, which is especially relevant due to potential consequences of the stroke and caused degree of disability).
\end{abstract}

Keywords. person-centred care services, tool support, stroke rehabilitation

\section{Introduction}

The PCC as innovative approach in health care has attracted attention as a proven concept for improvement of health outcomes by advancing cooperation and shared decision making between doctors and patients, with simultaneous increase of patient satisfaction [4][1]. Development of PCC services for stroke outpatient rehabilitation follows the following specific characteristics [3]: it is a chronic condition and thus the whole cycle of recovery is needed to be covered, after hospital treatment special focus shall be put on rehabilitation and further prevention of recurrent stroke through increased quality of life, self-efficacy, etc. The developed services are elaborated over evidence from neurology department of Clinical Centre in Montenegro, within scientific research project which is funded by the Ministry of Science of Montenegro.

\section{Methods}

Implemented methodology includes step-wised approach, consisting of several major steps: (i) analysis of best practices related to development of PCC services, (ii) analysis of the context for applications at Neurology department of the Clinical Centre of Montenegro [1], (iii) creation of the framework covering business processes and PCC concept, built upon well known concepts of model-driven engineering and software

${ }^{1}$ Corresponding author, Ramo Šendelj, University of Donja Gorica, Oktoih 1, 81000 Podgorica, Montenegro; E-mail: ramo.sendelj@\{gmail.com, udg.edu.me\}. 
product families [2], and (iv) prototyping and testing of specific IT services (in the form of mobile applications for patients and doctors). This approach ensures replicability to other domains of applications, thus being fully in line with strategical orientation for development of the Centre for PCC at Clinical Centre of Montenegro.

\section{Results}

Developed PCC services support identified features in outpatient rehabilitation business process model developed in [2]. It is implemented in the form of mobile application for patients (connected with external devices, like smart phones, etc.) and web/mobile application for doctors supporting detailed view on rehabilitation process of patients, definition of corrective measures (highly relevant for exercises for motoric rehabilitation, pain reduction medications, etc.) (currently available on Montenegrin language) (Fig.1., Fig.2.). Specific module for prediction of the rehabilitation process, as well as for prediction of recurrent strokes for each specific patient is developed. The predictive system is developed by using existing databases and stroke patient registries [1][2], while it is expected to increase the accuracy by exploring data collected by active system usage.

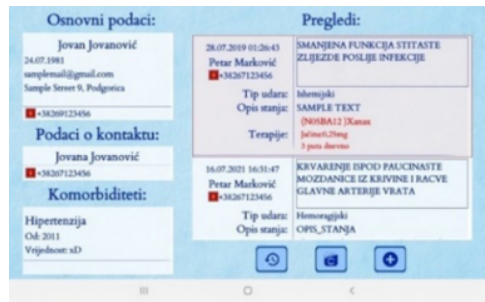

Figure 1. PCC service for stroke outpatient rehabilitation: Module for doctors

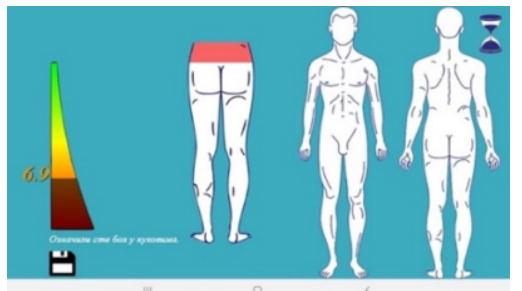

Figure 2. PCC service for stroke outpatient rehabilitation: Module for patients

\section{Discussion}

The developed services present initial step in creation of PCC healthcare services in Clinical Centre of Montenegro, which implementation has already shown several issues and challenges: necessity for (i) raising awareness among patients and development of partnership with patients, (ii) significant increase of IT health literacy, as well as (iii) holistic support during implementation process, (iv) development of tailored evaluation framework, etc. However, the established close cooperation between patients and doctors during the stroke rehabilitation process ensures greater confidence and a sense of security which directly increase the quality of life and healthcare prevention. Future work will be focused on making comprehensive evaluation and further tool support development.

\section{References}

[1] Ognjanović I, Šendelj R, Mantas J, Roganović M. Development of ICT Enhanced Person-Centred Care Services for Stroke Outpatient Rehabilitation. In: Proceedings of the 2021 10th Mediterranean Conference on Embedded Computing (MECO), 2021, p. 1-4. 
[2] Ognjanović I, Lewandowski R, Šendelj R, Krikščiunien D, Eraković J. Model Driven Approach for Development of Person-Centred Care in Stroke Rehabilitation. In: J. Mantas et al., editors. The Importance of Health Informatics in Public Health during a Pandemic 272: IOSPress; 2020.

[3] Hubbard IJ, et al. Adherence to Clinical Guidelines Improves Patient Outcomes in Australian Audit of Stroke Rehabilitation Practice. Archives of Physical Medicine and Rehabilitation. 2012; 93: 965-71.

[4] Ekman N, et al. A state-of-the-art review of direct observation tools for assessing competency in personcentred care. International Journal of Nursing Studies. 2020; 109: 103634. 